\title{
PEMODELAN PIFTICY THEORY (SPIRIT OF SELF TENACITY AND EFFICACY THEORY) DAN DAMPAKNYA TERHADAP KINERJA PERSONAL DENGAN SA-CILUS THEORY (STAR ASSURANCE BASED SOCIAL STATUS THEORY) SEBAGAI VARIABEL MEDIASI Studi pada Dosen PTS di Kota Palembang
}

EKA MUZALFITRI RIDWAN

Fakultas Ekonomi, Universitas Sjakhyakirti, Palembang

The role and the function of a lecturer in a private college is very crucial in accordance with a lecturer can serve some college students in the shape of scientific education, knowledge, science, and even new technologies. So, in this matter how hard a lecturer's job to fulfill and satisfy the students' skill and education until they can get their hope like academic degrees. The classical problems that researcher finds not only from the research gap but also from empirical studies found that lecturers' prosperities and their recognitions of their skill and expert and even scientific researches are very apprehensive until their motivation at work is low, not loyal to the job, unsatisfied, and even overloading job without any recognitions from their foundation or institution. This research has found that PIFTICY theory and SA-CILUS theory are successfully generated as new theories or postulates to contribute science addition and development in human resource management and organizational behavior until problems in personal performance in this research can be solved. the method of this research using AMOS programme that results PIFTICY significantly influences on personal performance with the grade of 0,963 and SA-CILUS as a mediating variables that influences on PIFTICY with the grade of 0,045 . Not only the grand theoretical model in this resaerch is proper but also empirical model in this research can be proper and accepted as a new-research construct.

Keywords: Pifticy, Sa-Cilus, Budaya Keluarga, Budaya Kerja, Kinerja Personal 


\section{PENDAHULUAN}

Dosen merupakan sebuah profesi mulia sebagai penghantar ilmu, pengetahuan dan teknologi yang dapat membantu berbagai pihak baik pemerintah, perusahaan, maupun lembaga-lembaga lainnya baik sektor bisnis maupun sosial sebagai pengguna sumberdaya manusia yang siap pakai, berintelektual tinggi, berintegritas, dan berwawasan luas serta bahkan siap pakai baik secara teoritis maupun praktik. Namun sangat disayangkan, profesi dosen ini secara umum kurang mendapat perhatian dan penghargaan secara serius kiprah dan kontribusinya bagi kalangan pemegang perguruan tinggi swasta atau yayasan dan para pengelolanya yang dibuktikan dengan mininya gaji (tidak sesuai dengan UMR), beban kerja yang tidak sesuai dengan derajat kesejahteraan, kurangnya penghargaan dari lembaga baik pengelola maupun pemilik yayasan perguruan tinggi swasta, dan sekelumit permasalahn lainnya yang dialami dosen PTS. Kondisi ini sering menimbulkan dampak sosial bagi diri dosen PTS itu sendiri dan layangan terhadappara peserta didiknya yaitu kalngan mahasiswa seperti kurangnya semangat kerja dan kepuasan kerja dosen PTS hingga derajat kinerja yang menurun, disiplin kerja yang semakin menurun, derajat loyalitas yang menurun terhadap lembaga, bahkan capaian pelaksanaan tridharma PT setiap dosen PTS yang tidak optimal (data temuan peneliti bulan Februari hingga Desember 2017 pada APTISI Sumsel).

Penelitian ini dilakukan pada dosen perguruan tinggi swasta di wilayah Kota Palembang baik berbentuk akademi, politeknik, sekolah tinggi, maupun universitas. Peneliti menemukan bahwa permasalahan klasik dosen PTS di kota Palembang berupa kecilnya derajat kesejahteraan di kalangan dosen yang umumnya berupa gaji yang tidak sesuai dengan standar sehingga berdampak pada derajat motivasi kerjanya. Selain permasalahan tersebut di atas diangkat melalui penelitian empirik peneliti namun juga penulis mencoba mengkaitkan permaslahan tersebut dari aspek research gap dari hasil penemuan kalangan ilmuan manajemen di beberapa jurnal internasional. Menurut Mathis Schulte (2016) dengan penelitiannya berjudul organizational climate systems and psycho- logical climate perceptions: A cross-level study of climate-satisfaction relationships menemukan bahwa seorang karyawan akan termotivasi untuk bekerja jika adanya dorongan atau dukungan yang kuat dari anggota keluarga akan pekerjaan atau profesi yang diembannya serta kepercayaan dari pihak lembaganya sehingga akan berdampak pada derajat kepuasan kerjanya dan berakhir pada peningkatan derajat kinerja individu. Kondisi tersebut diperkuat pula oleh Carr, J. Z., Schmidt, A. M., Ford, J., \& DeShon, R. P. (2013). melalui jurnal penelitiannya berjudul climate perceptions matter: A meta-analytic path analysis relating molar climate, cognitive and affective states, and individual level work outcome menemukan bahwa kondisi kerja kerja yang mendukung setiap individu (pekerja) dapat berdampak secara signifikan terhadap motivasi kerja dan pada gilirannya berpengaruh dan berkorelasi kuat dengan derajat kinerja setiap individu yang bekerja dalam lingkungannya. Penelitian lainnya yang mendukung Malthis dan Carr adalah Per Eisele (2011) yang menemukan bahwa budaya kerja yang harmonis dan mengakui keberaadaan setiap individu yang bekerja padanya akan berdampak kuat pada peningkatan derajat kinerja nya secara individual.

Pada penelitian ini peneliti juga berupaya membandingkan pendapat ilmuan lainya yang berseberangan pendapat melalui research gap yaitu antara lain: Anderson, N.R., \& West, M.A (2016) dengan judul penelitian: The team climate inventory: Development of the TCI and its applications in teambuilding for innovativeness, dan Brown, $\mathrm{S}$. P., \& Leigh, T. W. (2017) dengan jurnalnya: A new look at psychological climate and its relationship to job involvement, effort, and performance, serta D'Amato, A., \& Zijlstra, D. (2008) dengan artikel ilmiahnya yang berjudul Psychological climate and individual factors as antecedents of work outcomes masing-masing menemukan bahwa budaya kerja yang tegas dan berpihak pada disiplin kerja yang ketat akan mendorong motibvasi kerja yang tinggi, begitupula dengan budaya kerja yang membiasakan dengan kondisi kerja penuh dengan konflik berupa perbedaan pendapat di setiap lini kerja justru akan merangsang setiap diri individu agar lebih kreatif dan inovatif dalam bekerja yang pada gilirannya akan meningkatkan kinerja dan 
kepuasan kerja.

Budaya kerja merupakan suatu kondisi yang dicirikan dalam bentuk kebiasaan (custom) yang dilakukan secara turun temurun dalam suatu organisasi hingga menjadi suatu symbol kegiatan dalam setiap aktivitasnya (Thayer, S. 2008 dan Schneider, B., 1990).

Motivasi kerja adalah suatu kondisi berupa daya dorong yang dimiliki individu atau kelompok dalam suatu lingkungan kerja baik secara internal maupun eksternal (Lepper, M. R., Sethi, S., Dialdin, D., \& Drake, M., 2017, Csikszentmihalyi, M., Abuhamdeh, S., \& Nakamura, J, 2011, dan George A. Marcoulides and Adele Eskeles Gottfried, 2017).

Kinerja yaitu suatu capaian akhir yang dimiliki oleh setiap individu atau kelompok kerja dengan acuan standar sebagai pre-determinan dengan target yang telah atau sedang dijalankan dalam suatu organisasi kerja (Christopher Orpen, 2011, Alderfer, C., 1999, dan Jirapa Chalatharawat, 2009)

Hubungan budaya organisasi dengan motivasi kerja adalah kuat dan berpengaruh sangat signifikan terhadap derajat kinerja individu dan kelompok dalam suatu organisasi kerja (Sally Sledgea, *, Angela K. Miles, and Samuel Coppagec, 2016, Deci, E. L., \& Ryan, R. M, 2011, dan Day, H. I., Berlyne, D. E., \& Hunt, D. E., 2013, serta Eccles, J. S., 2010). Budaya organisasi dan motivasi juga dapat mempengaruhi kinerja seseorang melalui derajat kepusan kerja yang dimilikinya. Artinya jika kondisi seseorang benar-benar mencintai pekerjaannya yang dibuktikan dengan derajat loyalitas yang tinggi terhadap pekerjaannya, komunikasi yang harmonis dengan sesama rekan kerja, dan berani bertanggung jawab terhadap segala risiko pekerjaan yang diembannyamaka sangat berpotensi dapat meningkatkan derajat kinerjanya baiksevara individu maupun kelompok Connolly, J.J., \& Viswesvaran, C., 2015, Arvey, R.D., Bouchard, T.J. Jr., Segal, N.L., \& Abraham, L.M., 2015, dan Christian Dormann and Doris Fay, 2017)

Kinerja individu dapat pula dipengaruhi oleh keadaan jiwa (mood) seseorang dalam lingkungan kerjanya sehingga selain budaya kerja dan motivasi kerja, mood seseorang juga berperan banyak dalam peningkatan derajat kepuasan kerja hingga kepada kinerja seseorang (Dormann, C., \& Zapf, D, 2012, danFisher, C.D., 2015)

Adapun banyaknya jumlah dosen PTS di wilayah kota Palembang yang berhasil dijadikan sebagai sampel dalam penelitian ini dapt digambarkan pada Tabel 1 .

Jumlah sampel sebanyak 172 orang dosen tersebut memiliki latar belakang pendidikan minimal strata dua (S2) yang linear dengan bidang disilpin keilmuannya bahkan ada yang telah mencapai status guru besar dan memiliki pengalaman mengajar minimal 3 tahun (telah memiliki NIDN dan jenjang kepangkatan akademik minimal asisten ahli)

Data permasalahan dosen PTS di kota Palembang yang berhasil peneliti kumpulkan selama kurang lebih 9 (sembilan) bulan pada tahun 2017 melalui penyebaran lembar kuesioner yang secara langsung ditujukan pada dosen dan pimpinan lembaga PTS (rektor, ketua sekolah tinggi, dan direktur) disajikan pada Tabel 2.

Tabel 1

Jumlah Dosen PTS Kota Palembang Sebagai Sampel Penelitian Tahun 2017

\begin{tabular}{lc}
\hline \multicolumn{1}{c}{ Bentuk PTS } & $\begin{array}{c}\text { Jumlah Dosen PTS Kota Palembang } \\
\text { (orang) }\end{array}$ \\
\hline Akademi & 33 \\
\hline Politeknik & 16 \\
\hline Sekolah Tinggi & 44 \\
\hline Universitas & 79 \\
\hline \multicolumn{1}{c}{ T o t a I } & $\mathbf{1 7 2}$ \\
\hline
\end{tabular}

Sumber: Data yang diolah, 2017 
Tabel 2

Permasalahan Sosial Dosen PTS dan Dampaknya terhadap Kinerja Personal di wilayah Kota Palembang Tahun 2017

PTS

\section{yang dialami dosen PTS Kota \\ Palembang Selama Tahun 2017 \\ (Kasus)}

Permasalahan Sosial

1. Masalah disiplin kerja dosen yang memburuk (58 Kasus)

Akademi

2. Masalah loyalitas kerja dosen yang rendah terhadap lembaga dan profesi (14 kasus)

3. Motivasi kerja yang yang menurun (102 kasus)

4. Kinerja dosen yang memburuk (99 kasus)

1. Masalah disiplin kerja dosen yang memburuk (61 Kasus)

Politeknik

2. Masalah loyalitas kerja dosen yang rendah terhadap lembaga dan profesi (22 kasus)

3. Motivasi kerja yang yang menurun (93 kasus)

4. Kinerja dosen yang memburuk (124 kasus)

1. Masalah disiplin kerja dosen yang memburuk (95 Kasus)

Sekolah Tinggi

2. Masalah loyalitas kerja dosen yang rendah terhadap lembaga dan profesi (91 kasus)

3. Motivasi kerja yang yang menurun (133 kasus)

4. Kinerja dosen yang memburuk (111 kasus)

1. Masalah disiplin kerja dosen yang memburuk 117 Kasus)

Universitas

2. Masalah loyalitas kerja dosen yang rendah terhadap lembaga dan profesi (71 kasus)

3. Motivasi kerja yang yang menurun (168 kasus)

4. Kinerja dosen yang memburuk (149 kasus)

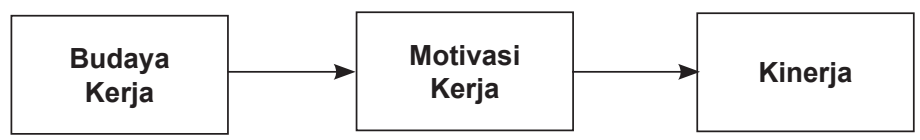

Gambar 1. Grand Theoretical Model

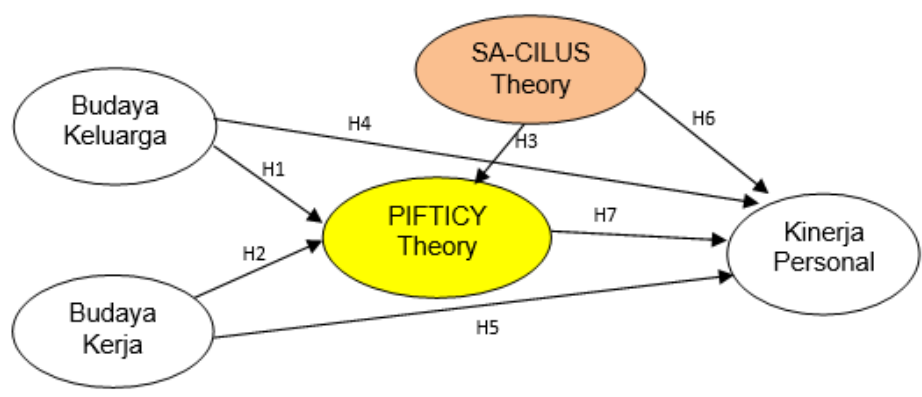

Gambar 2. Empirical Model 
Penelitian ini menghasilkan 2 (dua) model penelitian yaitu grand Theoretical Model (model teoritis) dan Empirical Model (model empirik). Adapun model teoretis dapat disajikan seperti pada Gambar 1.

Gambar 1 merupakan model utama dalam penelitian ini dimana variabel eksogen (sebagai variabel independen) akan berdampak terhadap derajat motivasi kerja seseorang dan pada gilirannya akan mempengaruhi derajat kinerja (sebagai variabel dependen) dalam organisasi kerja. Sementara gambar 2 menyajikan model teoretis yang merupakan operasionalisasi dari model utama dimana variabel budaya kerja dipecah menjadi budaya keluarga dan budaya kerja, motivasi kerja dikembangkan menjadi sebuah postulasi baru (sebagai novelty penelitian) bernama PIFTICY theory (Spririt of Self Tenacity and Efficacy) dan SA-CILUS theory (Star Assurance based Social status) sebagai variabel mediasi yang memediasi variabel PIFTICY theory yang juga merupakan sebuah postulasi baru dalam penelitian ini hingga menuju variabel kinerja personal sebagai variabel dependen.

Pada Gambar 2 disajikan pula 7 (tujuh) hipotesis yang merupakan rangkaian pelengkap untuk menunjukkan bahwa penelitian ini merupakan penelitian yang bersifat analitik deskriptif kuantitatif, dengan rincian sebagai berikut:

Hipotesis 1 (H1) : Semakin baik derajat budaya keluarga maka semakin tinggi derajat PIFTICY seseorang

Hipotesis 2 (H2) : Semakin baik derajat budaya kerja maka semakin tinggi derajat PIFTICY seseorang

Hipotesis 3 (H3) : Semakin tinggi derajat SA-

CILUS seseorang maka semakin tinggi derajat PIFTICY seseorang

Hipotesis 4 (H4) : Semakin baik derajat budaya keluarga maka semakin tinggi derajat kinerja seseorang

Hipotesis 5 (H5) : Semakin baik derajat budaya kerja maka semakin tinggi derajat kinerja seseorang

Hipotesis 6 (H6) : Semakin tinggi derajat SACILUS seseorang maka semakin tinggi derajat kinerja seseorang
Hipotesis 7 (H7) : semakin tinggi derajat PIFTICY seseorang maka semakin tinggi derajat kinerja seseorang

\section{METODE PENELITIAN}

Pada penelitian ini digunakan metode penelitan survey dimana seluruh populasi penelitian digunakan sepenuhnya meskipun beberapa responden tidak mengembalikan lembar kuesioner yang diberikan. Penelitian ini menggunakan metode pendekatan structural equation modeling (SEM) karena konstruk penelitian yang digunakan memiliki variabel eksogen dan variabel endogen lebih dari dua varibel penelitian dengan dimensi dan indikator penelitian yang cukup komplek baik dari aspek kuantitas dimensi penelitiannya maupun konten kajian teoretikalnya.

Populasi penelitian berjumlah 179 orang dosen namun yang berhasil dikumpulkan dan bisa diolah sebagai data penelitian berjumlah 172 orang dosen melalui lembaran kuesioner yang telah dipersiapkan sebelumnya. Adapun penentuan jumlah sampel dapat dilakukan dengan mengalikan 5 dengan jumlah indikator dalam variabel penelitian (Marcoulides, G. A., \& Hershberger, S. L. , 2000) yaitu: 5 x 21 indikator $=105$ responden (minimal), maka dengan jumlah responden 172 orang sudah dapat dianggap ideal karena telah melebihi standar jumlah minimal responden yang ditetapkan.

Teknik penetapan sampel dilakukan melalui pendekatan simple purposive sampling yaitu mengambil seluruh responden dosen PTS di kota Palembang baik dariakademi, politeknik, sekolah tinggi,dan universitas dengan pengalaman minimal 2 (dua) tahun.

Adapun variabel penelitian beserta indikatornya dapat digambarkan sebagai berikut:

Skala pengukuran pada penelitian ini menggunakan skala pengukuran interval dengan range skala antara 1 hingga 10 , yang bertujuan agar memberikan kebebasan yang seluasnya kepada para responden dalam menjawab pilihan 
Tabel 3

Variabel, Pengukuran, dan indikator (dimensi) Penelitian

\begin{tabular}{|c|c|c|}
\hline Variabel & Pengukuran & Indikator (Dimensi) \\
\hline Budaya Keluarga & $\begin{array}{l}\text { Diukur dengan menggunakan } 4 \text { item } \\
\text { dimensi yang dikembangkan oleh } \\
\text { Carr, J. Z., Schmidt et.all (2013) }\end{array}$ & $\begin{array}{l}\text { 1. Tekanan ekonomi } \\
\text { 2. Tekanan kehidupan di masa depan } \\
\text { 3. Citra diri } \\
\text { 4. Gaya hidup }\end{array}$ \\
\hline Budaya Kerja & $\begin{array}{l}\text { Diukur dengan menggunakan } 5 \text { item } \\
\text { dimensi yang dikembangkan oleh } \\
\text { Brown, S. P., \& Leigh, T. W. (2017). }\end{array}$ & $\begin{array}{l}\text { 5. Gaji yang minim } \\
\text { 6. Tidak adanya pengakuan dari lembaga. } \\
\text { 7. Rekrutmen dosen atas nepotism dan kolusi } \\
\text { 8. Senioritas dalam bekerja } \\
\text { 9. Karir yang bersifat "status quo" }\end{array}$ \\
\hline $\begin{array}{l}\text { SA-CILUS (Star Assur- } \\
\text { ance based Social Sta- } \\
\text { tus) }\end{array}$ & $\begin{array}{l}\text { Diukur dengan menggunakan } 4 \text { item } \\
\text { dimensi yang dikembangkan oleh } \\
\text { Arvey (2015), Dormann (2012), dan } \\
\text { Mathis Schulte (2016) }\end{array}$ & $\begin{array}{l}\text { 10. Adanya pengakuan atau legalitassebagai } \\
\text { dosen tetap } \\
\text { 11. Adanya pengakuan/legalitas akan peker- } \\
\text { jaan tetap } \\
\text { 12. Adanya legalitas akan gaji tetap } \\
\text { 13. Adanya pengakuan masyarakat akan ek- } \\
\text { sistensi dosen dalam masyarakat }\end{array}$ \\
\hline $\begin{array}{l}\text { PIFTICY (Spirit of Self Te- } \\
\text { nacity and Efficacy) }\end{array}$ & $\begin{array}{l}\text { Diukur dengan menggunakan } 4 \text { item } \\
\text { dimensi yang dikembangkan oleh } \\
\text { Christopher Orpen (2011) dan Lep- } \\
\text { per (2017) }\end{array}$ & $\begin{array}{l}\text { 14. Percaya akan skill \& kemampuan } \\
\text { 15. Percaya bahwa peluang profesi menjan- } \\
\text { jikan ke depannya } \\
\text { 16. Percaya akan kemampuan membangun } \\
\text { teknologi dengan kebaruan. } \\
\text { 17. Percaya akan dukungan profesinya dari } \\
\text { masyarakat/lingkungannya }\end{array}$ \\
\hline Kinerja Personal & $\begin{array}{l}\text { Diukur dengan menggunakan } 4 \text { item } \\
\text { dimensi yang dikembangkan oleh } \\
\text { Per Eisele (2011), Fisher (2015), } \\
\text { Eccles (2010), Csikszentmihalyi } \\
\text { (2011), dan George A. Marcoulides } \\
\text { (2017) }\end{array}$ & $\begin{array}{l}\text { 18. Produktivitas penelitian yang tingi } \\
\text { 19. Prestasi berupa pengembangan ide-ide } \\
\text { baru bagi perguruan tinggi } \\
\text { 20. Harmonisasi dalam komunikasi dan interak- } \\
\text { si / bekerja } \\
\text { 21. Disiplin kerja }\end{array}$ \\
\hline
\end{tabular}

Sumber: Data yang Diolah, 2017

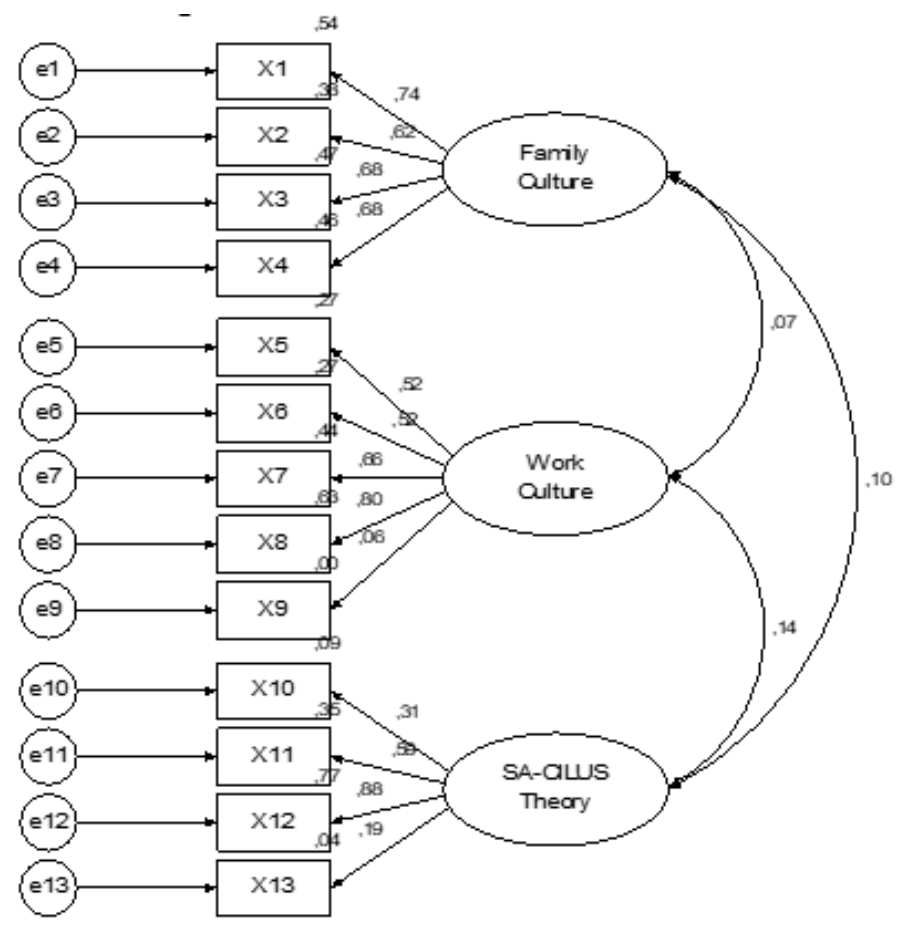

Gambar 3. Exogenous Variable/Construct 
jawaban pada lembar kuesioner yang disediakan sehingga hasil penelitian ini terhindar dari jawaban responden yang bersifat skala sikap karena tidak menggunakan skala pengukuran nominal dan atau ordinal.

Metode pengumpulan data pada peneltian ini yaitu dengan cara observasi langsung pada PTS yang ada di kota Palembang dan melakukan penyebaran kuesioner kepada responden yang dituju yaitu kalangan dosen yayasan PTS.

Teknik analisis data dilakukan dengan cara merumuskan persamaan struktural kausalitas, uji validitas dan reliabilitas, dan evaluasi model penelitian empirik melalui uji kesesuaian statistic (cut-off value)

\section{HASIL PENELITIAN}

Untuk hasil penelitian, peneliti menggunakan pendekatan analisis SEM (Structural equation Modelling) yang dilengkapi program AMOS (Analysis of Moment Structure) sebagai tool yang membantu dalam menganalisis dan mengkalkulasi data kuantitatif hingga interpretasi data yang telah diolah.

Dari hasil pengolahan data pada gambar 3 untuk penggunaan konstruk variabel eksogen pada penelitian ini dihasilkan nilai yang layak sehingga dapat dilanjutkan atau diterima baik melalui uji konfirmatori variabel eksogen dan uji kesesuian model (goodness of Fit Test).

Berdasarkan uji konfirmatori variabel didapat hasil bahwa loading factor variabel budaya keluarga secara umum di atas 0,5 yaitu $X_{1}$ sebesar $0,72, X_{2}$ sebesar $0,62, X_{3}$ sebesar $0,69, X_{4}$ sebesar 0,68 , dan begitupula dengan variabel budaya kerja yaitu $X_{5}$ sebesar $0,52, X_{6}$ sebesar $0,52, X_{7}$ sebesar 0,66, $\mathrm{X}_{8}$ sebesar 0,80 , kecuali $\mathrm{X}_{9}$ sebesar 0,05. Pada variabel SA-CILUS theory masingmasing bernilai $\mathrm{X}_{10}$ sebesar 0,31, $\mathrm{X}_{11}$ sebesar 0,59, $\mathrm{X}_{12}$ sebesar 0,88, dan $\mathrm{X}_{13}$ sebesar 0,19. Jika dievaluasi dari uji keseuaian model (Goodness of Fit Test) model variabel eksogen tersebut sangat baik dengan rincian probabilitas $0,06 \geq 0,05$, RMSEA $0,071 \leq 0,08, \mathrm{CMIN} / \mathrm{df} 1,185 \leq 2,00$, TLI $0,98 \geq$ 0,95, dan CFI 0,98 $\geq 0,95$.

Selanjutnya juga diperlukan evaluasi terhadap variabel endogen seperti yang disajikan pada
Gambar 4 sebagai berikut:

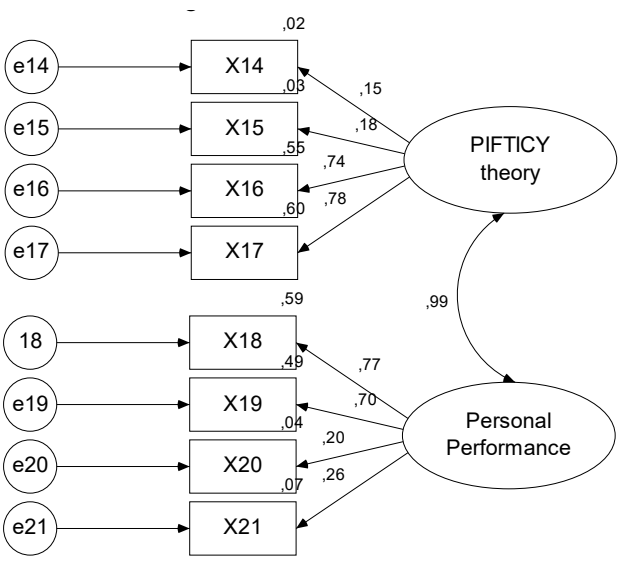

Gambar 4. Endogenous Variable/Construct

Uji konfirmatori variabel dihasilkan loading factor variabel PIFTICY Theory yang secara umum di atas 0,5 yaitu $\mathrm{X}_{14}$ sebesar $0,15, \mathrm{X}_{15}$ sebesar $0,18, X_{16}$ sebesar $0,74, X_{17}$ sebesar 0,78 , dan begitupula dengan variabel kinerja personal yaitu $\mathrm{X}_{18}$ sebesar 0,77, $\mathrm{X}_{19}$ sebesar 0,70, $\mathrm{X}_{20}$ sebesar $0,20, X_{21}$ sebesar 0,26. Jika dievaluasi dari uji keseuaian model (Goodness of Fit Test) model variabel eksogen tersebut cukup baik dengan rincian probabilitas $0,09 \geq 0,05$, RMSEA $0,014 \leq 0,08$, CMIN/df $1,44 \leq 2,00$, TLI $0,96 \geq 0,95$, dan CFI $0,97 \geq 0,95$.

Secara umum modelempirik dalam penelitian ini layak untuk dilanjutkan dan diterima karena telah memenuhi kelayakan atas uji konfirmatori dan uji kelayakan model (Goddness of Fit Test) yang disajikan pada Gambar 5.

Pada Gambar 5, yang menunjukkan empirical model dapat dievaluasi reliabel atau tidaknya suatu data dan valid atau tidaknya data kuesioner yang disebarkan dengan menggunakan alfa crobach sebesar 0,4 (Marcoulides, G. A., \& Hershberger, S. L, 2000) sebagai patokan atau dasar perbandingan dengan alfa reliability dan validity hasil perhitungannya. Hasil perhitungan empirical model dengan program AMOS didapat hasil bahwa baik alpha validitas maupun reliabilitas di atas nilai alpha cronbach 0,4 seperti yang ditampilkan pada tabel 4 sebagai berikut: 


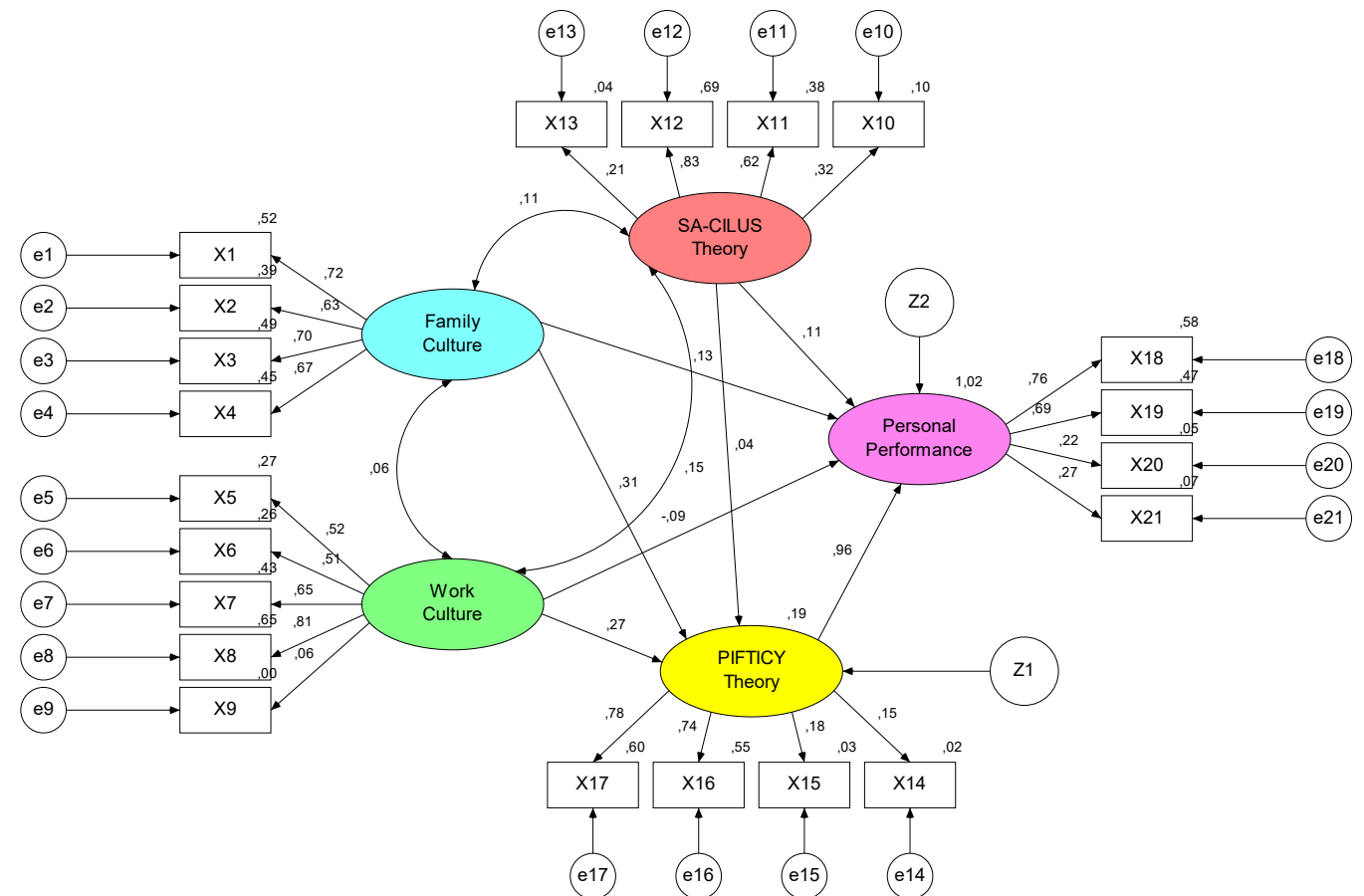

Gambar 5. Empirical Research Model

Tabel 4

Nilai Reliabilitas dan Validitas serta Indikator Variabel

\begin{tabular}{clcc}
\hline No & \multicolumn{1}{c}{ Variabel Penelitian } & Alpha Reliabilitas & Alpha Validitas \\
\hline 1. & Budaya Keluarga & $0,85(>0,40)$ & $0,71(>0,40)$ \\
\hline 2. & Budaya Kerja & $0,81(>0,40)$ & $0,69(>0,40)$ \\
\hline 3. & SA-CILUS Theory & $0,79(>0,40)$ & $0,77(>0,40)$ \\
\hline 4. & PIFTICY Theory & $0,68(>0,40)$ & $0,84(>0,40)$ \\
\hline 5. & Kinerja Personal & $0,81(>0,40)$ & $0,59(>0,40)$ \\
\hline
\end{tabular}

Sumber: Data diolah, 2018

Tabel 5

Assessment of Normality

\begin{tabular}{ccccccc}
\hline Variable & $\min$ & $\max$ & skew & c.r. & kurtosis & c.r. \\
\hline X21 & 1,000 & 10,000 &,- 758 & $-1,056$ &,- 917 & $-2,455$ \\
\hline X20 & 1,000 & 10,000 &,- 608 & $-1,257$ & $-1,231$ & $-1,295$ \\
\hline X19 & 1,000 & 10,000 &,- 061 &,- 328 & $-1,324$ & $-1,544$ \\
\hline X18 & 1,000 & 10,000 &,- 106 &,- 568 & $-1,314$ & $-1,517$ \\
\hline X10 & 1,000 & 10,000 & $-1,227$ & $-1,572$ & -079 &, 210 \\
\hline X11 & 1,000 & 10,000 & $-1,088$ & $-1,826$ &,- 143 &,- 384 \\
\hline X5 & 1,000 & 10,000 &,- 886 & $-1,745$ &,- 908 & $-2,430$ \\
\hline X6 & 1,000 & 10,000 &,- 959 & $-1,134$ &,- 667 & $-1,784$ \\
\hline X7 & 1,000 & 10,000 &,- 945 &,- 060 &,- 784 & $-2,098$ \\
\hline X8 & 1,000 & 10,000 &,- 906 &,- 853 &,- 760 & $-2,036$ \\
\hline X9 & 1,000 & 10,000 & $-1,062$ &,- 688 &,- 176 &,- 471 \\
\hline X1 & 1,000 & 10,000 &,- 154 &,- 827 & $-1,508$ & $-1,036$ \\
\hline X2 & 1,000 & 10,000 &,- 312 & $-1,672$ & $-1,419$ & $-1,799$ \\
\hline X3 & 1,000 & 10,000 &,- 296 & $-1,583$ & $-1,617$ & -1329 \\
\hline X4 & 1,000 & 10,000 &,- 373 & $-1,999$ & $-1,458$ & $-1,902$ \\
\hline Multivariate & & & & & 10,349 & 2,184 \\
\hline
\end{tabular}

Sumber: Data yang Diolah, 2018 
Penilaian lainnya dapat ditinjau dari aspek uji nomalitas (assessment of normality) dimana standar nilai untuk uji ini dengan menggunakan nilai critical ratio $(\mathrm{CR}) \pm 2,58$ atau $<2,58$ dan atau $>$ -2,58 (Marcoulides, G. A., \& Hershberger, S. L., 2000). Tabel 5 menampilkan besarnya nilai CR yang lebih dari -2,58 dan kurang dari 2,58 sehingga data untuk model empirik dapat dikatakan normal, yaitu seperti yang ditampilkan pada Tabel 5 .

Selanjutnya jika ditinjau dari uji multivariate outlier dapat digunakan dengan cara pendekatan uji jarak Mahalanobis (Mahalanobis Distance) dengan acuan standar nilai diupayakan lebih kecil dari nilai Chi-square tabel $\left(<\chi_{\text {tabel }}^{2}\right.$, jumlah dimensi penelitian; $\alpha=0,001)$ maka besarnya chi-square tabel pada model penelitian ini adalah $\chi_{\text {tabel }}^{2}=$ 46,797 (21; $\alpha=0,001)$ dengan chi-square uji $\mathrm{Ma}$ halanobis Distance adalah lebih kecil dari $\chi_{\text {tabel }}^{2}$ seperti yang tertera pada Tabel 6 .

Tabel 6.

Observations farthest from the centroid (Mahalanobis distance)

\begin{tabular}{cccc}
\hline $\begin{array}{c}\text { Observation } \\
\text { number }\end{array}$ & $\begin{array}{c}\text { Mahalanobis } \\
\text { d-squared }\end{array}$ & p1 & p2 \\
\hline 16 & 36,826 &, 018 &, 953 \\
\hline 91 & 36,036 &, 022 &, 889 \\
\hline 105 & 35,705 &, 024 &, 774 \\
\hline
\end{tabular}

Sumber: Data yang Diolah, 2018

Hasil penelitian ini dapat disimpulkan bahwa model empirik pada penelitian ini layak dan dapat diterima sebagai penemuan baru (novelty) baik pada variabel penelitian, indikator peneltian, konstruk penelitian pada variabel eksogen dan variabel endogen serta konstruk penelitian secara terpisah melalui uji konfirmatori variabel sehingga dapat berkontribusi bagi pengembangan ilmu melalui pengembangan teori baru yang dapat dijadikan acuan bagi penelitian berikutnya untuk terus dikembangkan. Dari hasil telaah AMOS pada model empirik tersebut dihasilkan bahwa PIFTICY sangat berpengaruh pada derajat peningkatan kinerja personal yaitu sebesar 0,96 yang tentunya kondisi ini didukung karena adanya variabel mediating yang mendukung munculya PIFTICY yaitu kondisi SA-CILUS sebesar 0,04, namun secara langsung SA-CILUS yang dimiliki seseorang ternyata hanya berpengaruh kecil terhadap peningkatan derajat kinerja seseorang sebesar
0,11. Budaya keluarga dan budaya kerja berpengaruh secara langsung terhadap besar kecilnya derajat PIFTICY seseorang masing-masing sebesar 0,31 dan 0,27. Sementara, budaya keluarga juga bisa berpengaruh positif secara langsung terhadap kinerja personal sebesar 0,13 namun budaya kerja justru secara langsung berpengaruh negatif terhadap besarnya derajat kinerja personal.

Secara simpulan, derajat kinerja seorang dosen dapat ditingkatkan jika dosen tersebut mampu mengkondisikan dirinya untuk tetap gigih dan percaya diri dalam menjalani profesinya meskipun kesejahteraan dari organisasi yang menaunginya (PTS) tidak mendukung dirinya.

\section{PEMBAHASAN}

Penelitian ini berhasil menemukan teori baru (kebaruan/novelty) dalam bentuk postulasi/teori dan model penelitian dalam bentuk empirical model. Temuan baru yang berhasil dipecahkan dalam penelitan ini adalah adanya dua teori baru bernama PIFTICY Theory (Spirit of Self tenacity and efficacy) dan SA-CILUS Theory (Star Assurance based Social Status).

PIFTICY merupakan suatu kondisi atau keadaan yang dialami seseorang untuk tetap gigih dan percaya diri dalam melakukan dan menyelesaikan tugas dan tanggung jawabya meskipun organisasi yang menaunginya tidak memberikan reward yang sebanding dengan usaha yang telah atau sedang dicapainya. Kondisi PIFTICY berpotensi dapat meningkatkan kinerja individu (novelty peneliti, 2018)

SA-CILUS merupakan pengakuan publik terhadap diri seseorang berupa status sosial yang tinggi dan berwibawa dengan jaminan karir, masa depan dan pengaruh sosial yang tinggi dan luas di berbagai aspek pekerjaan dan atau profesi lainnya. Kondisi SA-CILUS seseorang berpotensi kuat dapat mempengaruhi derajat PIFTICY seseorang (novelty peneliti, 2018).

Diri pribadi seseorang pada dasarnya perlu adanya dukungan yang tidak saja secara materil namun yang paling penting adalah immaterial (faktor kejiwaan). Jika rasa percaya diri seorang dosen PTS dan kegigihannya dapat dipertahankan bahkan dapat ditingkatkan maka akan berpen- 
garuh secara segnifikan terhadap kepuasan kerja dan kinerjanya. Hal lain yang dapat menguntungkan jika PIFTTICY seorang dosen dapat ditingkatkan karena adanya SA-CILUS adalah:

1. SA-CILUS (Star Assurance based Social Status) seorang dosen PTS akan membangkitkan perasaaan bangga pada diri sendiri (Self Pride) akan status dirinya yang memiliki profesi selaku ilmuan dan peneliti yang sampai saat ini masih sangat dihargai dan dijunjung tinggi oleh masyarakat luas dari berbagai kalangan sebagai profesi yang mulia, berperan tinggi dalam mencerdaskan bangsa, pembentuk karakter anak bangsa di kemudian hari, pembentuk estetika dan etika bagi anak bangsa, panutan bagi masyarakat, berjiwa mulia, dan sebagai sumber ilmu yang tidak luntur dikekang waktu dan zaman.

2. Dengan adanya self pride seorang dosen PTS di atas maka akan membentuk jiwa pribadi yang gigih, kokoh dan percaya diri dalam menjalankan profesinya (terutama tridharma perguruan tinggi) meskipun tingkat kesejahteraan (seperti gaji, tunjangan, dan atau penghargaan lainnya) dari lembaga PTS yang menaunginya tidak cukup mendukung/support diri pribadi dosen tersebut dalam menjalankan profesinya.

3. Kepercayaan diri seorang dosen PTS (Self Efficacy) dalam menjalankan profesinya akan jauh lebih terdongkrak maju jika adanya dukungan moril dari pihak keluarga berupa budaya keluarga yang positif seperti turut mendukung dan mencintai profesi dosen yang sedang diemban oleh anggota keluarganya, sehingga besar peluang dosen tersebut dalam dirinya untuk meningkatkan motivasi intrinsiknya dalam menjalankan profesi tersebut dalam bentuk kegigihan dan keuletan dalam bekerja tanpa mengenyampingkan self-integrity yang dimiliki.

4. Bagi pemilik (yayasan) dan pengelola (rektor, dekan, ketua, dan direktur) PTS di kota Palembang sudah selayaknya memperhatikan nasib para dosennya berupa peningkatan derajat kesejahteraan yang seimbang dengan kinerja yang telah dicapai mengingat dosen merupakan ujung tombak kelancaran pelaksanaan akademik sebuah PTS (mesin penggerak dan image builder) sekaligus salah satu ujung tombak item dalam upaya peningkatan akreditasi sebuah PTS di semua aspek. Hal lainnya juga harus menjadi renungan bagi pemilik (yayasan) dan pengelola PTS di kota Palembang bahwa dosen adalah SDM yang mulai langka untuk didapat di kemudian hari karena adanya temuan symptoms bahwa banyak para sarjana-sarjana (S1 dan S2) yang mulai enggan memilih pekerjaan atau profesi sebagai dosen dengan alasan tingkat kesejahteraan yang sangat minim dan kurang adanya pengakuan atas setiap prestasi yang dikerjakannya sehingga kebanyakan para sarjana tersebut dewasa ini lebih memilih bekerja di perusahaan-perusahan yang berorientasi profit-minded.

5. Bagi pemerintah sudah selayaknya menjadi renungan bahwa perlu dukungan materil bagi dosen PTS berupa peningkatan dana bantuan tanpa adanya diskriminasi antara dosen PTN dengan dosen PTS yang berkeinginan kuat untuk melakukan pengembangan riset dan teknologi sesuai dengan keahliannya sehingga sebagai alat pemicu bagi dosen tersebut untuk berkinerja lebih baik lagi. 


\section{REFERENCES}

Alderfer, C. (1999), Existence, Relatedness and Growth: Human Needs in Organizational Settings, New, York: Free Press.

Anderson, N.R., \& West, M.A. (2016). The team climate inventory: Development of the TCI and its applications in teambuilding for innovativeness. European Journal of Work and Organizational, Behavior, 19, $235-258$.

Arvey, R.D., Bouchard, T.J. Jr., Segal, N.L., \& Abraham, L.M. (2015). Job satisfaction: Environmental and genetic components. Journal of Applied Psychology, 74, 187-192.

Asosiasi Perguruan Tinggi Swasta Wilayah Sumatera selatan (APTISI Sumsel), 2017

Brown, S. P., \& Leigh, T. W. (2017). A new look at psychological climate and its relationship to job involvement, effort, and performance. Journal of Applied Psychology, 81, 358 - 368.

Carr, J. Z., Schmidt, A. M., Ford, J., \& DeShon, R. P. (2013). Climate perceptions matter: A metaanalytic path analysis relating molar climate, cognitive and affective states, and individual level work outcomes. Journal of Applied Psychology, 88, 605-619.

Christian Dormann and Doris Fay, A State-Trait Analysis of Job Satisfaction: On the Effect of Core Self-Evaluations, APPLIED PSYCHOLOGY: AN INTERNATIONAL REVIEW, 2017, 55 (1), $27-51$

Christopher Orpen, The effects of formal mentoring on employee work motivation, organizational commitment and job performance The Learning Organization, Volume $4 \cdot$ Number $2 \cdot 2011 \cdot \mathrm{pp}$. 53-60 (C) MCB University Press · ISSN 0969-6474

Connolly, J.J., \& Viswesvaran, C. (2015). The role of affectivity in job satisfaction: A meta-analysis. Personality and Individual Differences, Journal of Applied Psychology, 29, 265-281.

Csikszentmihalyi, M., Abuhamdeh, S., \& Nakamura, J. (2011). Flow. In A. J. Elliott \& C. S. Dweck (Eds.), Handbook of competence and motivation. (pp. 598-608). New York: Guilford Press.

D’Amato, A., \& Zijlstra, D. (2008). Psychological climate and individual factors as antecedents of work outcomes. European Journal of Work and Organizational Psychology, 17, 33 - 54.

Day, H. I., Berlyne, D. E., \& Hunt, D. E. (2013). Intrinsic motivation: new direction in education. Toronto: Holt, Rinehart \& Winston Press Canada.

Deci, E. L., \& Ryan, R. M. (2011). Self-determination theory and the facilitation of intrinsic motivation, social development, and well-being. American Psychologist, 55, 68-78, (2011)

Dormann, C., \& Zapf, D. (2012). Social support, social stressors at work and depression: Testing for main and moderating effects with structural equations in a 3-wave longitudinal study. Journal of Applied Psychology, 84, 874-884. 
Eccles, J. S. (2010). Subjective task value and the Eccles et al. model of achievement- related choices. Handbook of competence and motivation (pp. 105-121). New York: Guilford Press.

Fisher, C.D. (2015). Mood and emotions while working: Missing pieces of job satisfaction? Organizational Behavior and Human Decision Processes, Journal of Applied Psychology 21, 185-202.

George A. Marcoulides and Adele Eskeles Gottfried, A Latent Curve Model of Parental Motivational Practices and Developmental Decline in Math and Science Academic Intrinsic Motivation, Journal of Educational Psychology 2017, Vol. 101, No. 3, 729-739

Jirapa Chalatharawat, 2009, Accounting nformation Usefulness for Performance Evaluation and Its Impact on The Firm Success: An Empirical Investigation of Food Manufacturing Firms in Thailand, REVIEW OF BUSINESS RESEARCH, Volume 9, Number 2, 2009

Lepper, M. R., Sethi, S., Dialdin, D., \& Drake, M. (2017). Intrinsic and extrinsic motivation: A developmental perspective Developmental psycho thology: Perspectives on adjustment, risk, and disorder (pp. 23-5 New York: Cambridge University Press.

Marcoulides, G. A., \& Hershberger, S. L. (2000). Multivariate statistical methods: A first course. Mahwah, NJ: Erlbaum.

Mathis Schulte, Organizational climate systems and psychological climate perceptions: A cross-level study of climate-satisfaction relationships, Journal of Occupational and Organizational Psychology (2016), 79, 645-671

Per Eisele, Psychological climate and its relation to work performance and well-being: The mediating role of Organizational Citizenship Behavior (OCB), Baltic Journal of Psychology, 2011, 12 (1, 2), 4-21

Sally Sledgea, Angela K. Miles, and Samuel Coppagec, What role does culture play? A look at motivation and job satisfaction among hotel workers in Brazil, The International Journal of Human Resource Management, Vol. 19, No. 9, September 2016, 1667-1682

Schneider, B. (1990). Organizational climate and culture. San Francisco: Jossey-Bass.

Thayer, S. (2008). Psychological climate and its relationship to employee engagement and organizational citizenship behaviors. Unpublished doctoral dissertation. 